\title{
Glucose Tolerance and Insulin Response in Atherosclerosis
}

\author{
J. M. SLOAN, ${ }^{*}$ M.D. ; J. S. MACKAY,† B.SC. ; B. SHERIDAN, $\ddagger$ F.I.M.L.T.
}

\begin{abstract}
Summary: Oral glucose tolerance tests were carried $\checkmark$ out on 51 men with atherosclerotic peripheral vascular disease, none of whom were known diabetics or had suffered recent myocardial infarction. The plasma insulin and blood sugar responses were compared with 47 ageand sex-matched controls. There was no significant difference in obesity between the two groups. The patient group showed an increased plasma insulin response with a delay in return to fasting levels, and the blood sugar response was similar. These results suggest that hyperinsulinaemia and hyperglycaemia are often associated with atherosclerosis, and may have a role in its aetiology.
\end{abstract}

\section{Introduction}

The association between abnormalities of carbohydrate metabolism and increased prevalence of atherosclerosis are well known. Increased incidence of atherosclerotic disease has been shown in patients with reduced glucose tolerance (Keen et al., 1965; Ostrander et al., 1967) and the converse situation of a reduction of glucose tolerance in atherosclerosis sufferers also applies (Kingsbury, 1968). More recently an increased insulin response to oral glucose in survivors of myocardial infarction has been reported (Peters and Hales, 1965; Tzagournis et al., 1967) and it has been suggested that insulin may play an important part in atherogenesis (Kuo, 1968; Stout and Vallence-Owen, 1969). The purpose of this study was to investigate glucose tolerance and insulin response in patients with advanced atherosclerosis having no history of recent infarction.

\section{Subjects and Methods}

The study was carried out on a total of $98 \mathrm{men}, 51$ in the patient group and 47 controls. The mean age of the patients was 54.1 years (range 38-64) and that of the controls 50.4 years (range 37-63). Myocardial infarction is known to have profound and often prolonged effects on carbohydrate metabolism (Datey and Nanda, 1967; Devlin and Stephenson, 1968). In order to minimize this it was decided to study patients suffering from intermittent claudication caused by atherosclerosis. The aetiology of the condition was confirmed by arteriography in each case.

Eleven of the patients had a history of myocardial infarction. The minimum time interval between infarction and investigation was five months; only three patients had suffered infarction within the previous year. No member of the control or patient groups was a known diabetic, but five patients had a family history of diabetes and 16 gave a history of atherosclerotic disease in relatively young relations. All the patients showed absence of one or more leg pulses, but no sepsis or gangrene was present at the time of testing, and no participant was receiving any drug therapy.

The controls consisted of male volunteers who had been admitted to hospital for minor surgical procedures but were otherwise healthy. Each member was questioned to exclude a history of cardiovascular disease, as recommended by Rose

\footnotetext{
* Registrar, Department of Pathology.

+ Registrar, Departmer Biochemist.

‡ Senior Technician, Department of Biochemistry. Royal Victoria Hospital, Belfast 12 .

Present address: I.C.I. Pharmaceuticals Division, Mereside; Alderley Park, Macclesfield, Cheshire.
}

(1962). They showed no evidence of atherosclerotic disease on physical or E.C.G. examination; all leg pulses were easily palpable. No known diabetics were included. None of the controls had a family history of diabetes or premature atherosclerosis.

Fifty-gramme oral glucose tolerance tests were performed and plasma insulin and blood sugar levels were determined on venous samples while fasting and at $30,60,90$, and 120 minutes after glucose administration. All tests were begun between 7 and 8 a.m., after a fast for 10-12 hours. Plasma insulin levels were assayed by the method of Hales and Randle (1963). Assays were carried out in batches of about 150 samples. All assays were done at least in duplicate and all samples from one patient were included in the same batch. So far as possible each batch contained equal numbers of samples from patient and control groups to avoid any bias due to interbatch variation.

Blood sugar was estimated by a modification of Hoffman's (1937) method, the AutoAnalyzer (Technicon) being used. Total insulin or blood sugar response was estimated with the formula $\mathrm{A}+2 \mathrm{~B}+2 \mathrm{C}+2 \mathrm{D}+\mathrm{E}$, where $\mathrm{A}$ is the fasting level and $B, C, D$, and $E$ are the succeeding levels throughout the test. This formula has recently been used by Abrams et al. (1969).

Obesity is known to influence insulin secretion; thus an index of obesity was determined by means of a formula based on that of Edwards and Whyte (1962):

Obesity index $=$ S.F. $+\mathrm{H}^{2} \times 10^{-4}$

where S.F. is the sum of the skinfold thicknesses (in $\mathrm{cm}$.) at three standard sites (paraumbilical, infrascapula, and midtriceps) and $\mathrm{H}$ is the height of the subject (in $\mathrm{cm}$.). Skinfold thickness was measured with Harpenden skinfold calipers.

All subjects were investigated before surgery to avoid the metabolic effects of the trauma.

\section{Results}

The mean obesity index of the controls was 9.61 (S.D. 3.7) and that of the patients 9.87 (S.D. 3.50). The difference between the two groups was not significant. The distribution of plasma insulin values at the various time intervals was skewed to the left, but logarithmic conversion led to more normal distribution. A similar phenomenon has been previously reported (Boyns et al., 1969). Blood sugar levels showed normal distribution. The mean plasma insulin levels and blood sugar levels in both groups at the various time intervals are shown in Figs. 1 and 2. The characteristic feature of the patient group was an increased insulin response with a sluggish return to fasting levels. The blood sugar response was similar.

The mean $\log$ insulin levels at the various time intervals for patients and controls are given in Table I. Comparison was carried out using a split plot analysis of variance (Cochran and Cox, 1957). The "insulin area," a measure of the total insulin response, is also included. Table II shows blood sugar levels at similar intervals. The plasma insulin levels of the patients were significantly higher at one, one and a half, and two hours. The patients' total insulin response was also significantly higher. Similar differences were present in the blood sugar levels.

Normal subjects have been classified into "early," "intermediate," and "late" insulin responders according to the speed with which the postglucose insulin levels returned to within 
TABLE I.-Comparison of the Log Mean Insulin Levels and Insulin Area Using a Split Plot Analysis of Variance

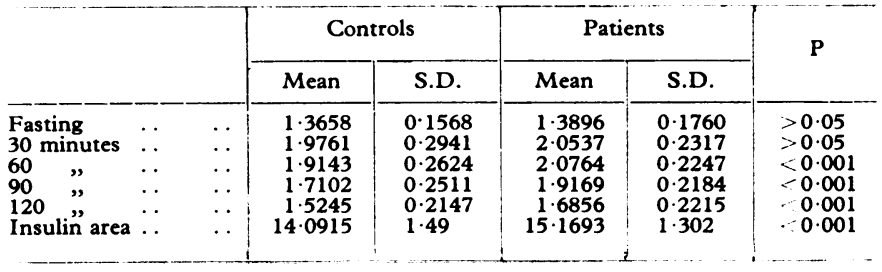

TABLE II.-Comparison of Mean Blood Sugar Levels in $\mathrm{mg} .1100 \mathrm{ml}$. and Blood Sugar Area Using a Split Plot Analysis of Variance

\begin{tabular}{|c|c|c|c|c|c|c|}
\hline & & \multicolumn{2}{|c|}{ Controls } & \multicolumn{2}{|c|}{ Patients } & \multirow{2}{*}{$\mathbf{P}$} \\
\hline & & Mean & S.D. & Mean & S.D. & \\
\hline 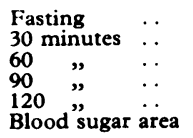 & & $\begin{array}{r}84 \cdot 72 \\
140 \cdot 38 \\
114 \cdot 66 \\
92 \cdot 87 \\
79 \cdot 91 \\
860 \cdot 47\end{array}$ & $\begin{array}{r}7.6 \\
22.7 \\
34.9 \\
23.6 \\
13.7 \\
154.9\end{array}$ & $\begin{array}{r}83 \cdot 25 \\
142 \cdot 24 \\
142 \cdot 45 \\
118 \cdot 37 \\
92 \cdot 25 \\
981 \cdot 6\end{array}$ & $\begin{array}{r}9 \cdot 6 \\
27 \cdot 3 \\
37 \cdot 3 \\
24 \cdot 4 \\
24 \cdot 3 \\
199 \cdot 3\end{array}$ & $\begin{array}{l}>0.5 \\
=0.5 \\
<0.001 \\
\therefore 0.001 \\
.0 .05 \\
.0 .01\end{array}$ \\
\hline
\end{tabular}

$20 \mu$ units of the fasting level (Buchanan and McKiddie, 1967). To accommodate all subjects in this study a "very late" group was created consisting of those whose insulin levels were over $20 \mu$ units above the fasting level after two hours.

In Table III the patients and controls are divided according to the speed of their insulin response. There is a striking difference between the two groups. Eleven controls and 23 patients showed abnormal glucose tolerance according to the criteria laid down by the British Diabetic Association (Fitzgerald and Keen, 1964).

\section{Discussion}

This study confirms the common occurrence of hyperinsulinaemia in association with atherosclerotic vascular disease which has been reported in survivors of myocardial infarction (Peters and Hales, 1965; Tzagournis et al., 1967). The study of patients with intermittent claudication and no recent myocardial infarcts reaffirms that the hyperinsulinaemia is not a reaction to previous infarction. Welborn et al. (1966) also reported mild hyperinsulinaemia in
TABLE III.-Members of Both Groups Classified According to the Speed of Insulin Response (Percentages in Parentheses)

\begin{tabular}{|c|c|c|c|c|c|}
\hline & & Early & Intermediate & Late & Very Late \\
\hline $\begin{array}{l}\text { Controls. . } \\
\text { Patients .. }\end{array}$ & .. & $\begin{array}{c}7(14 \cdot 9) \\
1(2 \cdot 0)\end{array}$ & $\begin{array}{c}18(38 \cdot 3) \\
6(11 \cdot 8)\end{array}$ & $\begin{array}{l}12(25 \cdot 5) \\
16(31 \cdot 4)\end{array}$ & $\begin{array}{l}10(21 \cdot 3) \\
28(54.9)\end{array}$ \\
\hline
\end{tabular}

a small number of patients with atherosclerotic peripheral vascular disease. In the present study it is unlikely that the insignificant difference in obesity of the two groups influenced the results.

Possibly the impaired mobility of the patient group may have influenced the results to some extent. All participants remained in bed during glucose tolerance testing to avoid the acute effects of exercise, but Davidson et al. (1966) noted a diminished insulin response to oral glucose in a small group of men after six weeks' strenuous physical training. This was accompanied by an increased blood sugar response. The relevance of these results to the present study is doubtful, however, because the control group consisted of men suffering from surgical conditions, such as inguinal hernia and haemorrhoids, which would tend to limit severe physical exercise. No attempt was made to assess the degree of mental stress to which the participants were exposed, but as all participants were facing the prospect of surgery it was felt that psychological factors which might influence the results by increased adrenocortical activity would apply equally to both groups.

Twenty-three $(45 \%)$ of the patients showed some abnormality of glucose tolerance, and the insulin response pattern in this group is very similar to that reported in maturity-onset diabetes (Seltzer et al., 1967)-that is, increased insulin response with a slow return to fasting levels. Danowski (1970) showed that the advent of glucose intolerance in adults may be associated with increased insulin response.

These results suggest that hyperinsulinaemia and hyperglycaemia are often associated with, and may be aetiological factors in, atherosclerosis. Experiments have indicated that insulin may increase lipid deposition on the arterial wall (Stout, 1968). It has also been suggested that insulin, which increases oxygen consumption of human intimal cells, may lead to localized hypoxia of the intima with subsequent increase in lipid accumulation (Robertson, 1968).

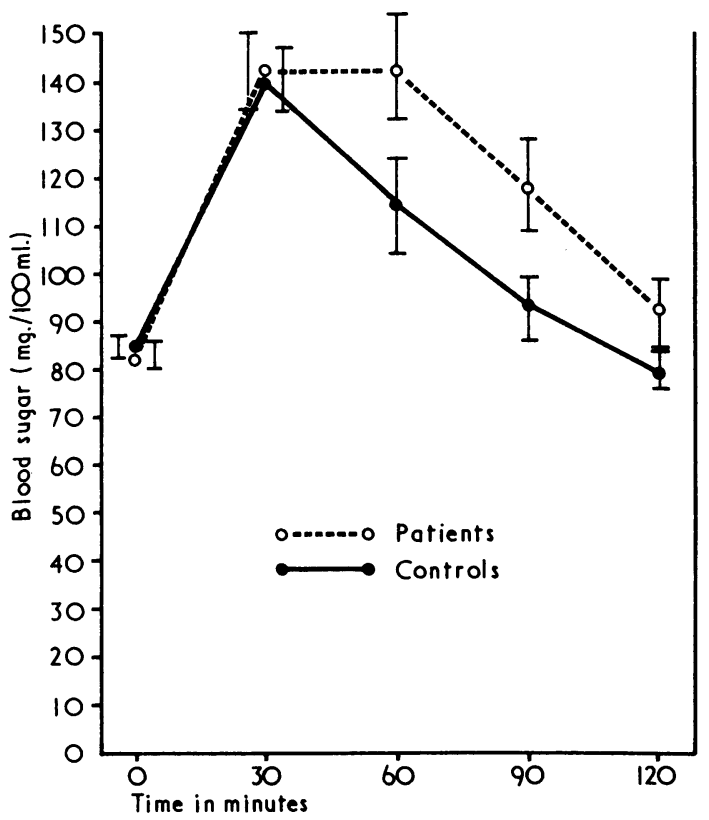

FIG. 2.-Mean blood sugar levels of the patient and control groups ( \pm 2 S.E. of mean) at the stated time intervals after glucose administration.
FIG. 1.-Mean plasma insulin levels of the patient and control groups ( $t 2$ S.E. of m zan) at the stated time intervals after glucose administration.

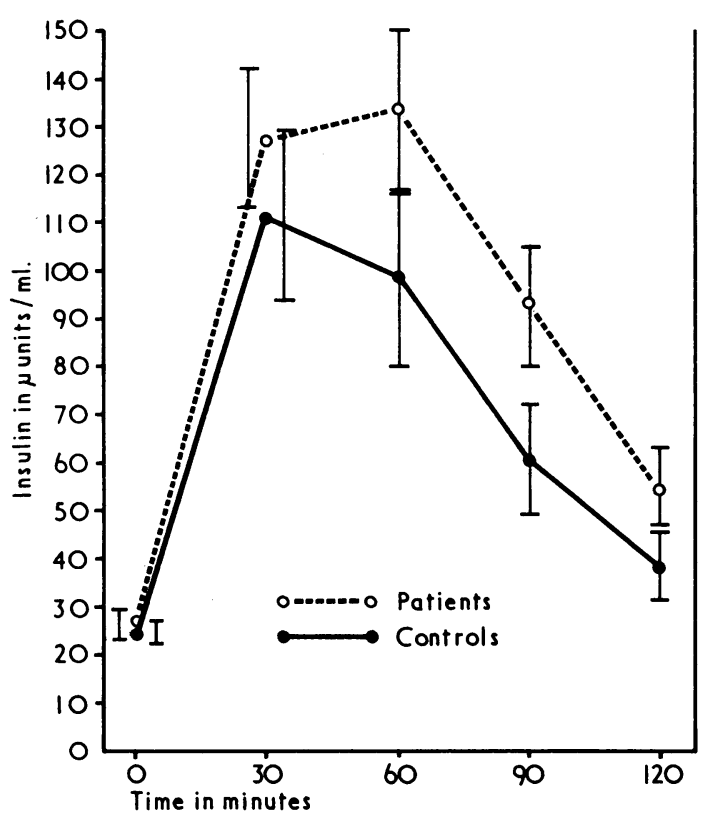


Atherogenesis may also be stimulated via the connexion which has been demonstrated between hyperglycaemia, hyperinsulinaemia, and hypertriglyceridaemia (Abrams et al., 1969).

Further studies on the atherogenic properties of insulin would appear to be warranted in the light of these results.

We thank Professor Sir John H. Biggart and Mr. D. W. Neill for their help and advice. We are also grateful to Dr. J. D. Merrett for his statistical advice.

Requests for reprints should be sent to Dr. J. M. Sloan.

\section{REFERENCES}

Abrams, M. E., Jarrett, R. J., Keen, H., Boyns, D. R., and Crossley, J. N. (1969). British Medical fournal, 1, 599.

Boyns, D. R., Crossley, J. N., Abrams, M. E., Jarrett, R. J., and Keen, H. (1969). British Medical fournal, 1, 595.

Buchanan, K. D., and McKiddie, M. T. (1967). Diabetologia, 3, 460.

Cochran, W. G., and Cox, G. M. (1957). In Experimental Design, 2nd edn. London, Chapman and Hall.
Danowski, T. S. (1970). Postgraduate Medical fournal, 46, 125.

Datey, K. K., and Nanda, N. C. (1967). New England fournal of Medicine, 276, 262 .

Davidson, P. C., Shane, S. R., and Albrink, M. J. (1966). Circulation, 33, suppl. 3, p.7.

Devlin, J. G., and Stephenson, N. (1968). Metabolism, 17, 999.

Edwards, K. D. G., and Whyte, H. M. (1962). Clinical Science, 22, 347.

Fitzgerald, M. G., and Keen, H. (1964). Lancet, 1, 1325.

Hales, C. N., and Randle, P. J. (1963). Lancet, 1, 200.

Hoffman, W. S. (1937). Journal of Biological Chemistry, 120, 51.

Keen, H., et al. (1965). Lancet, 2, 505.

Kingsbury, K. J. (1968). Postgraduate Medical fournal, 44, 944.

Kuo, P. T. (1968). Annals of Internal Medicine, 68, 449.

Ostrander, L. D., Neff, B. J., Block, W. D., Francis, T., and Epstein, F. H. (1967). Annals of Internal Medicine, 67, 34.

Peters, N., and Hales, C. N. (1965). Lancet, 1, 1144.

Robertson, A. L. (1968). Progress in Biochemical Pharmacology, 4, 305.

Rose, G. A. (1962). Bulletin of the World Health Organization, 27, 645

Seltzer, H. S., Allen, E. W., Herron, A. L., and Brennan, M. T. (1967) fournal of Clinical Investigation, 46, 323.

Stout, R. W. (1968). Lancet, 2, 702.

Stout, R. W., and Vallence-Owen, J. (1969). Lancet, 1. 1078.

Tzagournis, M., Seidensticker, J. F., and Hamwi, G. J. (1967). Annals of Internal Medicine, 67, 42.

Welborn, T. A., Breckenridge, A., Dollery, C. T., Rubenstein, A. H., and Fraser, T. R. (1966). Lancet, 1, 1336.

\title{
Urinary Tract Dilatation and Oral Contraceptives
}

\author{
P. B. GUYER, ${ }^{*}$ M.R.C.P., F.F.R. ; D. DELANY, $†$ D.M.R.D.
}

British Medical fournal, 1970, 4, 588-590

\begin{abstract}
Ummary: Six nulliparous patients were found to have overdistensiblity : of the upper urinary tract on excretion urography. Of these five had had persistent or recurrent urinary infections. All had been or were receiving oral contraceptives. Though overdistensibility associated with contraceptive therapy is unlikely to be life-threatening, it may be associated with increased patient morbidity.
\end{abstract}

\section{Introduction}

Six women who were referred for excretion urography showed overdistensibility of part of the upper urinary tract, a finding normally seen after pregnancy. Nevertheless, none of these patients had been pregnant, though all had at some time received cyclical oral hormone therapy for menstrual irregularity or contraception. This finding occurred incidentally during an investigation of overdistensibility of the female upper urinary tract.

\section{Clinical and Laboratory Features}

Five patients were referred for urography on account of persistent or recurrent urinary tract infection (Table I). The sixth was referred for investigation of loin pain. Before the injection they were all closely questioned about their symptoms, with particular reference to frequency, dysuria, and haematuria. We accepted a diagnosis of infection if any two of these three symptoms were present. The patients were also questioned about hormone therapy. Because many of them were referred by general practitioners, the excretion urograms were often performed three to four weeks after the acute symptoms had occurred. Most patients had at least one examination of a midstream specimen of urine, but the results of this correlated poorly with the clinical symptoms, since the midstream specimen showed bacteriological proof in only two

* Consultant Radiologist.

† Senior Registrar in Diagnostic Radiology.

$\boldsymbol{X}$-ray Department, Southampton General Hospital, Southampton. of the five patients in whom infection had been clinically diagnosed.

\section{Method}

All excretion urograms were performed the same way. A minimum of $50 \mathrm{ml}$. of Conray 420 was injected, and a fiveminute film of the renal areas was taken. Abdominal compression was then applied with the Cuthbert Andrews apparatus, inflated to a minimum pressure of $200 \mathrm{~mm}$. $\mathrm{Hg}$, and a 10minute film of the kidneys was taken. Provided these two films were satisfactory, full-length films of the urinary tract were taken on release of the abdominal compression and after micturition. Because of the possibility that the overdistensibility might be associated with ureteric reflux three of the six patients underwent micturating cystourethrography; in no instance did reflux occur.

What we consider to be normal compression effects during

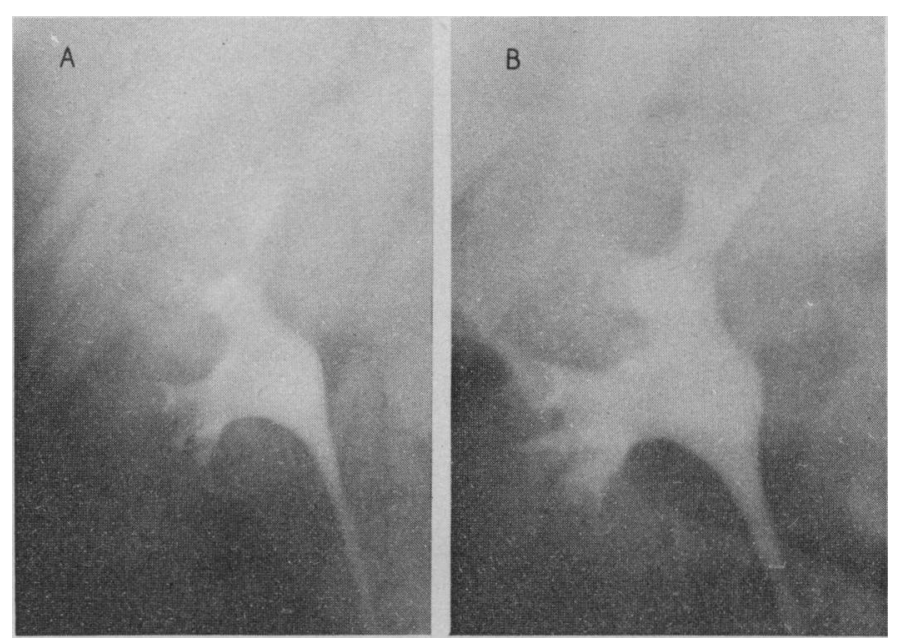

FIG. 1.-Normal I.V.P. A, Five-minute film before compression. B, Same patient-10-minute film with compression. The minor calices are better seen, but retain crisp definition at the fornices. 